Revue d'histoire de l'Amérique française

REVUE D.HISTOIRE DE L'AMÉRIQUE FRANÇAISE

MAURAULT, Olivier, p.a., p.s.s., Le Collège de Montréal, 1767-1967. Deuxième édition revue et mise à jour par Antonio Dansereau, p.s.s., 574 p. Montréal, 1967.\$10.00.

\title{
Léon Pouliot
}

Volume 21, numéro 4, mars 1968

URI : https://id.erudit.org/iderudit/302727ar

DOI : https://doi.org/10.7202/302727ar

Aller au sommaire du numéro

Éditeur(s)

Institut d'histoire de l'Amérique française

ISSN

0035-2357 (imprimé)

1492-1383 (numérique)

Découvrir la revue

Citer ce compte rendu

Pouliot, L. (1968). Compte rendu de [MAURAULT, Olivier, p.a., p.s.s., Le Collège de Montréal, 1767-1967. Deuxième édition revue et mise à jour par Antonio Dansereau, p.s.s., 574 p. Montréal, 1967. \$10.00.] Revue d'histoire de l'Amérique française, 21(4), 825-826. https://doi.org/10.7202/302727ar d'utilisation que vous pouvez consulter en ligne.

https://apropos.erudit.org/fr/usagers/politique-dutilisation/ 


\section{LIVRES ET REVUES}

MAURAULT, Olivier, p.a., p.s.s., Le Collège de Montréal, 1767-196\%. Deuxième édition revue et mise à jour par Antonio Dansereau, p.s.s., 574 pages. Montréal, 1967. $\$ 10.00$.

La première édition paraissait en 1918 sous le titre: Le Petit Séminaire de Montréal. La seconde conserve les titres et le contenu des cinq chapitres de Mgr Maurault. Elle est une mise à jour en ce sens que dans les cinq chapitres, M. Dansereau insère entre crochets [ ] des détails complémentaires qui aident à une meilleure intelligence du sujet. Il lui arrive même d'ajouter des faits intéressants que ne connaît pas la première édition. Pour ne donner qu'un exemple, au chapitre V, Les grands événements, il présente un récit circonstancié et judicieux de la "révolution" que connut le Collège en 1830, en se basant pour une large part sur l'étude donnée par Mgr Maurault aux Cahiers des Dix en 1937. Il signale que parmi les élèves inscrits au Collège cette année-là, plusieurs ont fait leur marque dans la vie; tels les deux fils de Papineau, Amédée et Lactance, son neveu Louis-Antoine Dessaulles, Pierre-Georges de Boucherville, secrétaire des Fils de la Liberté en 1837, Joseph Duquet, victime du soulèvement de 1838, et Georges-Etienne Cartier, qui prit part à la bataille de Saint-Denis. De plus, M. Dansereau nous fait participer à la vie du Collège pendant les 50 dernières années. Il en résulte une monographie qui est à la fois plus parfaite et plus complète.

Publié à l'occasion du deux-centième anniversaire de la fondation du Collège, l'ouvrage est dédié aux anciens élèves. A notre avis, il est susceptible d'intéresser un secteur beaucoup plus vaste par la richesse de son contenu, par un passé qu'il évoque parfois si près et si loin de nous et que nous n'avons pas le droit de reléguer dans l'oubli parce qu'il fait parti de notre être collectif. En un temps où nos collèges classiques traditionnels sont en pleine transformation, il n'est pas sans profit de savoir un peu mieux comment le plus ancien et le plus vénérable de la région de Montréal est né, comment il a grandi, l'influence considérable qu'il a exercée non seulement sur la ville mais sur tout le Canada français; et cela grâce surtout au sérieux avec 
lequel les Messieurs ont compris et exercé depuis le début jusqu'à nos jours leur vocation de pédagogues chrétiens.

A la page 73, l'auteur rapporte le dire d'un Sulpicien de l'époque selon lequel l'Ecole de Droit rattachée au Collège SainteMarie se serait affiliée à l'Université Fordham de New-York. Il y a là un malentendu qu'il n'est peut-être pas inutile de dissiper. Il est vrai qu'en 1855, à la suggestion du fondateur de l'Ecole, Maximilien-Uncas Bibaud, et avec l'approbation du P. Félix Martin, s.j., l'Université jésuite de New-York décernait des doctorats honorifiques à quelques personnages canadiens; il est vrai que Bibaud s'était humblement placé sur cette liste de récipiendaires et que les autres étaient liés de près ou de loin à l'Ecole de Droit. Mais là s'arrêtent les relations entre celle-ci et Fordham. A notre connaissance, il n'y eut jamais d'affiliation. Les élèves de Bibaud accédaient à l'exercice de la profession non en vertu d'un diplôme universitaire quelconque, mais après un examen en bonne et due forme passé devant le Barreau.

L'ouvrage qui est relié et d'une superbe présentation, est écrit dans une langue simple, élégante et avec cette discrétion, nous allions dire cet effacement si caractéristique des Messieurs quand ils traitent de leur institut ou de leurs œuvres; ils se contentent de laisser parler les faits.

La deuxième édition du Collège de Montréal se termine par cinq appendices qui ont tous leur intérêt. Nous en signalerons ici deux à l'intention de la race des chercheurs sérieux qui se fait de plus en plus nombreuse aujourd'hui. Le IV e nous donne la liste des élèves de 1767 à 1966; on y trouve la date de leur entrée au collège, la durée de leur séjour, le lieu de leur origine et, quand la chose est possible, le genre de vie qu'ils ont embrassé plus tard (181-472). Le cinquième appendice nous offre la liste alphabétique des élèves pendant ces deux cents ans (473-566). A notre connaissance, c'est là un fait unique: réunir en un même volume et selon l'ordre alphabétique les noms de tous les jeunes qui pendant un si long espace de temps se sont succédé dans une même institution. Nous ne sommes pas sans soupçonner la somme de recherches que ces appendices ont coûtée à $M$. Dansereau et nous l'en remercions. Signalons enfin les nombreuses et élégantes illustrations: photographies évocatrices du passé et dessins dus à d'excellents artistes de chez-nous. En un mot, nous sommes en présence d'un très beau et d'un très bon livre et nous lui souhaitons le plus grand succès.

LÉON POULIOT, s.j. 